\title{
Occurrence of Foodborne Pathogens and Molds in Turkish Foods
}

\author{
Sebnem Ozturkoglu-Budak ${ }^{1,2}$
}

${ }^{I}$ Department of Dairy Technology, Faculty of Agriculture, University of Ankara, 06100 Ankara, Turkey ${ }^{2}$ CBS-KNAW Fungal Biodiversity Centre, Uppsalalaan 8, 3584 CT Utrecht, the Netherlands

A R T I C L E I N F O

Article history:

Received 09 December 2015

Accepted 03 May 2016

Available online, ISSN: 2148-127X

Keywords:

Foodborne pathogens

Salmonella

Escherichia

Listeria

Molds

${ }^{*}$ Corresponding Author:

E-mail: budak@ankara.edu.tr \begin{abstract}
A B S T R A C T
A survey of the occurrence of food pathogens like Salmonella, Listeria, Escherichia, Clostridium, Bacillus and Staphylococcus analyses were performed on 301 food samples from 8 different food categories such as dry legumes, milk products, meat products, fish, frozen foods, deserts, nuts and vegetables and fruits. Yeast and mold analyses were also performed on 364 food products from 9 main food categories such as dry legumes, milk products, meat products, seasonings, deserts, nuts, bee products, bakery products and dried fruits produced in Turkey. S. aureus and Salmonella were the most prevalent $(1.33 \%)$ of the six isolated pathogens. The species Cl. perfringens, L. monocytogenes and B. cereus were detected with the ratios of $1.00 \%, 0.66 \%$ and $0.66 \%$, respectively. Total yeast and molds occurrence were $1.65 \%$ and $9.06 \%$, respectively. Pathogens were detected in cream cheese, spinach, strawberry and cod fish most prevalently, whereas dried fig, chilli pepper, hazelnut and bakery products were determined as foods prone to the growth of molds. The results of this study suggest that faecal contamination of water needs to be prevented, and the production and storage conditions of food materials should be improved. These findings have implications for the use of these surveillance data in developing evidence-based food policy.
\end{abstract}

\section{Introduction}

The most prevalent foodborne pathogens that cause foodborne illness are; pathogenic Salmonella spp., Campylobacter jejuni, Listeria monocytogenes and E. coli O157:H7. These pathogens are the leading causes of bacterial enteric illness in industrialized countries (Anonymous, 2005).

Food-borne pathogens are the main source of foodborne through the consumption of contaminated food or beverages. The effects of foodborne illness can range from relatively minor discomfort to more serious symptoms such as fever, diarrhea, vomiting, dehydration, and even death. The acute illnesses caused by foodborne organisms present food safety challenges for the entire food distribution chain (WHO, 1992). There have been several reported surveys on contamination of foods with pathogens like Campylobacter, Salmonella, E. coli O157: $\mathrm{H} 7$ and L. monocytogenes. But these studies give only one or two pathogens in limited food categories.

Occurrence of Campylobacter, Salmonella, Listeria and shiga toxin producing $E$. coli serotypes was performed on 60 flocks of free-range chicken from 34 farms in the Basque Country (Northern Spain) (Esteban et al., 2008). Some research showed the presence of pathogens in farms; Delhalle et al., evaluated Salmonella and E. coli contamination at the Belgian post-harvest stages. E. coli counts were estimated in order to evaluate the levels of faecal contamination (Delhalle et al., 2009). Another study was performed on Escherichia coli
O157:H7 in cattle and sheep at slaughter, on beef and lamb carcasses and in raw beef and lamb products from retail butchers' shops in the Sheffield area (Chapman et al., 2001). A research on the presence of $L$. monocytogenes in milk-based products was designed at retail establishments (REs); pasteurized milk and Minas frescal cheese (MFC) were taken as samples and the contamination source(s) of these products in the corresponding dairy processing plan was identified (Brito et al., 2008). Another previously reported study (Prendergast et al., 2008) described the prevalence and characteristics of Salmonella recovered from pork abattoir cutting rooms in Ireland and the aim of this study was to assess the transmission patterns and persistence of particular strains in the full pork chain.

Molds are microorganisms that live on plant or animal matter. Generally, the studies on molds existence in foods are performed for some specific mold species and food types. But mostly, mycotoxins produced by mold species are examined instead of mold species themselves. Ochratoxin A (OTA) and Aflatoxin B1 (AFB1) are among the most frequent observed combinations of mycotoxins in different plant products (Speijers \& Speijers, 2004). There are some examples of survey research about mold contamination of foods. Mislivec et al. (1979) conducted a survey for the number of different mold species in 10 types of foods (wheat flour, corn meal, brown rice, figs, split peas, pinto beans, soybeans, 
walnuts, pecans, and peanuts) labeled organically grown. Surveys of mold species in water (Hageskal et al., 2008), OTA contamination in different commodities as cereals, coffee, meat, grape, cocoa beans (Amézqueta et al., 2009) were also carried out.

The objective of this study was to determine the prevalence, detection and characteristics of some foodborne pathogens and molds at the uncontrolled retail stage and to assess the circumstance in Turkey. Moreover, it aims to investigate the carriage of these microorganisms in foods from field, abbatoir or raw materals to consumption stage. A data on prevalence of the infection during production and at market are of particular importance for the development of a rational system of food safety interventions. However, no such data on multiple food-borne pathogens and simultaneous molds is available in different categories of foods. A study on food microbiology and safety containing a wide-range of microorganisms and popular food categories was therefore needed to examine the situation in local scale.

\section{Materials and Methods}

\section{Sample Collection}

A total of 301 samples from 7 popular food categories (21 sub-categories) were obtained as unpackaged products from district bazaar and retail outlets in Turkey from 2006 to 2010, for the detection and/or enumeration of foodborne pathogens. Moreover, yeast and molds analyses were performed on 364 food samples ( 9 food categories). Samples including traditional food products, spices, meat-based and milk-based products, nuts, raw materials and processed food products were selected among a various food stuff groups. Sampling for all analyses were performed according to the FAO manual of microbiological analyses in foods (Andrews 1992). Dry legumes, seasonings, nuts and dried fruits were taken as $100 \mathrm{~g}$ in duplicate and analysed after homogenization with a blender. Meat-based products, fish, deserts, bakery products were obtained as two different composite units of $375 \mathrm{~g}$ for each (divided into 4 aliquots). Cheese samples were prepared as $500 \mathrm{~g}$ composite sample and blend for 2 min with the suitable broth in terms of microorganism type. Vegetables and fruits were supplied as whole material and sample units were prepared by mixing the homogenized samples at least $200 \mathrm{~g}$. Sample units of each food category were indicated in Table 1 and Table 2 and represented by the letter ' $n$ '. All samples were taken to the laboratory at refrigeration temperature $\left(4-5^{\circ} \mathrm{C}\right)$. Sample weighing and division into aliquots were performed under aseptic conditions. Duplicate inoculations were carried out throughout the study.

\section{Bacterial Isolation and Identification}

Food samples were treated and analysed as consumed so as to give a better presence of food pathogens and levels of toxigenic molds and mycotoxins amount that might be ingested. For the detected/non-detected analysis from aliquot of $25 \mathrm{~g}$, each sample was diluted 1:10 for enrichment.
For Salmonella spp analyses, food samples of $25 \mathrm{~g}$ were homogenized in $225 \mathrm{~mL}$ of buffered peptone water (BPW, Merck, Germany) and incubated for 16-20 h at $37^{\circ} \mathrm{C}$. $0.1 \mathrm{~mL}$ of pre-enriched sample was used to inoculate $10 \mathrm{~mL}$ of the Rappaport-Vassiliadis medium (RV, Merck) and $10 \mathrm{~mL}$ of the pre-enriched sample was used to inoculate $100 \mathrm{~mL}$ of the selenite-cystine medium (SC, Merck). Samples were incubated at $42^{\circ} \mathrm{C}$ for $7 \mathrm{~h}$ (RV) and at $37^{\circ} \mathrm{C}(\mathrm{SC})$, respectively. Subsequently, streak plate technique was applied to two selective solid mediums: Brilliant Green Phenol Red Agar (BGFR, Merck) and Xylose Lysine Desoxycholate (XLD, Merck) agar for the isolation of typical colonies as mentioned in ISO 6579:2002. Both plates were incubated at $37^{\circ} \mathrm{C}$ for $24 \mathrm{~h}$. After incubation, five typical and/or suspected colonies with a typical halo were sub-cultured on Triple Sugar Iron Agar (Oxoid, UK), Urea Broth (Merck) and Lysine iron medium (Difco Laboratories, Detroit, MI) for identification.

Enrichment for L. monocytogenes was carried out according to the ISO 11290:-1:1996. $25 \mathrm{~g}$ sample was homogenized in $225 \mathrm{~mL}$ Half-Fraser broth. The suspensions were homogenized and incubated for $24 \mathrm{~h}$ at $30^{\circ} \mathrm{C}$. After incubation, $0.1 \mathrm{~mL}$ pre-enriched broth was transferred into $10 \mathrm{~mL}$ completely supplemented Fraser broth and incubated at $37^{\circ} \mathrm{C}$ for $48 \mathrm{~h}$. Two separate streak inoculations were performed after $24 \mathrm{~h}$ and $48 \mathrm{~h}$ on PALCAM (Merck) and/or Oxford Agar (Oxoid) and incubated at $37^{\circ} \mathrm{C}$ at $24 \mathrm{~h}$, if needed for $48 \mathrm{~h}$. All suspected colonies were streaked on Tryptone Soya Yeast Extract (TSYE) Agar, separately. Growth colonies were identified biochemically after $24 \mathrm{~h}$ incubation at $37^{\circ} \mathrm{C}$ with a commercial API Listeria system (bioMerieux, Marcy-I'Etoile, France).

To detect and isolate E. coli O157:H7 serotype, method of ISO 16654:2001 was used. Solid food samples were homogenized in modified Tryptic Soy Broth (mTS, Merck) in a ratio of $25 \mathrm{~g}$ sample: $225 \mathrm{ml}$ TS broth. Liquid food samples were directly added to these broths in the same ratio. All mixtures were incubated at $37^{\circ} \mathrm{C}$ for $24 \mathrm{~h}$. Enrichment was sub-cultured (streak plate method with a loop and/or $0.1 \mathrm{~mL}$ spread plate technique from the dilutions $10^{-3}, 10^{-4}, 10^{-5}$ ) onto Cefimixe Tellurite (CT) added Sorbitol MacConkey agar (SMAC, Merck) and incubated at $37^{\circ} \mathrm{C}$ for $24 \mathrm{~h}$. Growth colourless colonies on SMAC agar were isolated as suspected colonies and identified by $\mathrm{O} 157$ and $\mathrm{H} 7$ antiserum. E. coli $\mathrm{O} 157: \mathrm{H7}$ colonies were confirmed with Singlepath E. coli $\mathrm{O} 157$ test kits (Merck).

Clostridium perfringens were identified according to the method of ISO 7937:2004. Tryptose Sulfite Cycloserine (TSC, Merck) agar containing egg-yolk emulsion was used for sample inoculations after homogenization in Differential Reinforced Clostridial Broth (DRCM, Merck). Plates were incubated in an anaerobic jar at $35^{\circ} \mathrm{C}$ for $24 \mathrm{~h}$. Black colonies on petri dishes were suspected as $\mathrm{Cl}$. perfringens. These colonies were biochemically confirmed by gram-staining, motility test and with a commercial API Clostridium system (bioMerieux, France). 
Bacillus cereus analyses were performed as mentioned in ISO 7932:2004. Butterfield's Phosphate-buffered dilution water (1:10) was used for homogenization of Bacillus cereus and blended at high speed (18.000-21.000 rpm) for $2 \mathrm{~min}$. Serial dilutions from $10^{-2}$ to $10^{-6}$ were inoculated onto mannitol-egg-yolk polymyxin agar
(MYP, Merck) plates by spread plate technique. Plates were incubated at $30^{\circ} \mathrm{C}$ for $24 \mathrm{~h}$. Colonies surrounded by precipitate zone were suspected as Bacillus colonies. Confirmation was performed by motility test, Gram staining, reduction of nitrate, VP reaction, anaerobic utilization of glucose by Phenol Red Glucose Broth.

Table 1 Frequency of isolation of the different pathogens in randomly selected food samples

\begin{tabular}{|c|c|c|c|c|c|c|c|c|c|c|c|c|c|}
\hline \multirow{2}{*}{ Food category } & \multirow{2}{*}{ Food subgroup } & \multicolumn{2}{|c|}{ Sal } & \multicolumn{2}{|c|}{ Lmon } & \multicolumn{2}{|c|}{ Ecoli } & \multicolumn{2}{|c|}{ Clper } & \multicolumn{2}{|c|}{ Bcer } & \multicolumn{2}{|c|}{ Saur } \\
\hline & & $\mathrm{np}$ & $\% \mathrm{p}$ & $\mathrm{np}$ & $\% p$ & $\mathrm{np}$ & $\% p$ & $\mathrm{np}$ & $\% p$ & $\mathrm{np}$ & $\% p$ & $\mathrm{np}$ & $\% \mathrm{p}$ \\
\hline \multirow{2}{*}{ Dry legumes } & Lentil $(\mathrm{n}=5)$ & 0 & 0 & 0 & 0 & 0 & 0 & 0 & 0 & 0 & 0 & 0 & 0 \\
\hline & Rice $(n=5)$ & 0 & 0 & 0 & 0 & 0 & 0 & 0 & 0 & 0 & 0 & 0 & 0 \\
\hline \multirow{6}{*}{ Milk products } & White Cheese $(n=15)$ & 0 & 0 & 1 & 6.67 & 0 & 0 & 0 & 0 & 0 & 0 & 1 & 6.67 \\
\hline & Milk $(\mathrm{n}=18)$ & 0 & 0 & 0 & 0 & 0 & 0 & 0 & 0 & 1 & 6.6 & 0 & 0 \\
\hline & Kashar cheese $(n=15)$ & 0 & 0 & 0 & 0 & 0 & 0 & 0 & 0 & 0 & 0 & 0 & 0 \\
\hline & Yoghurt $(n=15)$ & 0 & 0 & 0 & 0 & 0 & 0 & 0 & 0 & 0 & 0 & 0 & 0 \\
\hline & Cream cheese $(n=15)$ & 0 & 0 & 0 & 0 & 0 & 0 & 1 & 6.67 & 0 & 0 & 2 & 13.33 \\
\hline & Milk powder $(n=12)$ & 0 & 0 & 0 & 0 & 0 & 0 & 0 & 0 & 0 & 0 & 0 & 0 \\
\hline \multirow{4}{*}{ Meat products } & Minced lamb meat $(n=20)$ & 0 & 0 & 1 & 5 & 0 & 0 & 0 & 0 & 0 & 0 & 1 & 5 \\
\hline & Minced chicken meat $(n=20)$ & 1 & 5 & 0 & 0 & 0 & 0 & 0 & 0 & 0 & 0 & 0 & 0 \\
\hline & Lamb meat $(n=15)$ & 0 & 0 & 0 & 0 & 0 & 0 & 0 & 0 & 0 & 0 & 0 & 0 \\
\hline & Chicken $(n=20)$ & 1 & 5 & 0 & 0 & 0 & 0 & 0 & 0 & 0 & 0 & 0 & 0 \\
\hline Fish & Cod fish $(n=12)$ & 0 & 0 & 0 & 0 & 0 & 0 & 1 & 8.3 & 1 & 8.3 & 0 & 0 \\
\hline Frozen foods & Frozen peas $(n=12)$ & 1 & 8.3 & 0 & 0 & 0 & 0 & 0 & 0 & 0 & 0 & 0 & 0 \\
\hline \multirow{2}{*}{ Deserts } & Small cakes with syrup $(n=10)$ & 0 & 0 & 0 & 0 & 0 & 0 & 0 & 0 & 0 & 0 & 0 & 0 \\
\hline & Sponge pastry rolls in syrup $(n=10)$ & 0 & 0 & 0 & 0 & 0 & 0 & 0 & 0 & 0 & 0 & 0 & 0 \\
\hline \multirow{2}{*}{ Nuts } & Hazelnut puree $(n=20)$ & 0 & 0 & 0 & 0 & 0 & 0 & 1 & 5 & 0 & 0 & 0 & 0 \\
\hline & Hazelnut $(\mathrm{n}=20)$ & 0 & 0 & 0 & 0 & 0 & 0 & 0 & 0 & 0 & 0 & 0 & 0 \\
\hline Vegetables & Parsley $(\mathrm{n}=16)$ & 1 & 6.25 & 0 & 0 & 0 & 0 & 0 & 0 & 0 & 0 & 0 & 0 \\
\hline & Spinach $(n=16)$ & 1 & 6.25 & 0 & 0 & 1 & 6.25 & 0 & 0 & 0 & 0 & 0 & 0 \\
\hline \multirow[t]{2}{*}{ Fruits } & Strawberry $(n=10)$ & 0 & 0 & 0 & 0 & 0 & 10 & 0 & 0 & 0 & 0 & 0 & 0 \\
\hline & Total sample $=301$ & 4 & $1.33 \%$ & 2 & $0.66 \%$ & 1 & $0.33 \%$ & 3 & $1.00 \%$ & 2 & $0.66 \%$ & 4 & $1.33 \%$ \\
\hline
\end{tabular}

Sal: Salmonella; Lmon: L.monocytogenes; Ecoli: E.coli O157:H7; Clper: Cl.perfringens; Bcer: B. Cereus; Saur: S.aureus; n: n positive; \%p: \% positive

Table 2 Frequency of isolation of the different yeast and mold species in randomly selected food samples

\begin{tabular}{|c|c|c|c|c|c|c|}
\hline \multirow{2}{*}{ Food category } & \multirow{2}{*}{ Food subcategory } & \multicolumn{2}{|c|}{ Yeast } & \multicolumn{2}{|c|}{ Mold } & \multirow{2}{*}{ Characterized species } \\
\hline & & $\mathrm{np}$ & $\% \mathrm{p}$ & np & $\% \mathrm{p}$ & \\
\hline \multirow{2}{*}{ Dry legumes } & Lentil $(n=5)$ & 0 & 0 & 0 & 0 & - \\
\hline & Rice $(n=5)$ & 0 & 0 & 1 & 20 & Aspergillus oryzae \\
\hline \multirow{4}{*}{ Milk products } & White Cheese $(\mathrm{n}=15)$ & 0 & 0 & 2 & 13.33 & Penicillium spp., A.flavus, Cladosporium spp. \\
\hline & Cream cheese $(n=15)$ & 0 & 0 & 1 & 6.66 & A.versicolor \\
\hline & Kashar cheese $(n=15)$ & 1 & 6.66 & 1 & 6.66 & A.flavus, Cladosporium spp. \\
\hline & Yoghurt $(n=15)$ & 0 & 0 & 1 & 6.66 & Muсоr spp. \\
\hline \multirow{2}{*}{ Meat products } & Chicken $(n=20)$ & 0 & 0 & 0 & 0.0 & - \\
\hline & Minced lamb meat $(n=20)$ & 1 & 5 & 1 & 5.0 & Cladosporium spp., Geotrichum spp. \\
\hline \multirow{4}{*}{ Seasonings } & Flour $(n=15)$ & 0 & 0 & 2 & 13.33 & Mucor spp., Rhizopus spp. \\
\hline & Nane $(n=15)$ & 0 & 0 & 0 & 0 & - \\
\hline & Kekik $(n=15)$ & 0 & 0 & 1 & 6.66 & A.niger \\
\hline & Chilli pepper $(\mathrm{n}=35)$ & 1 & 2.86 & 6 & 17.14 & $\begin{array}{l}\text { A.niger, Trichoderma spp., Microsporium audouinii, } \\
\text { A.terreus, A.flavus, Mucor spp., Cryptococcus neoformans }\end{array}$ \\
\hline \multirow{3}{*}{ Deserts } & $\begin{array}{l}\text { Sponge pastry rolls in syrup } \\
(\mathrm{n}=10)\end{array}$ & 1 & 10 & 0 & 0 & Zygosaccharomyces bailii, \\
\hline & Baba desert $(n=10)$ & 1 & 10 & 0 & 0 & Debaryomyces hansenii \\
\hline & $\operatorname{Jam}(\mathrm{n}=10)$ & 1 & 10 & 0 & 0 & Zygosaccharomyces rouxii \\
\hline \multirow{2}{*}{ Nuts } & Hazelnut $(\mathrm{n}=35)$ & 0 & 0 & 3 & 8.57 & A.flavus, A.parasiticus, A.niger \\
\hline & Hazelnut puree $(n=20)$ & 0 & 0 & 2 & 10 & A.flavus, A.parasiticus \\
\hline Bee products & Honey $(n=20)$ & 0 & 0.0 & 1 & 5 & Mucor spp. \\
\hline \multirow{2}{*}{ Bakery products } & Wheat Bread $(n=15)$ & 0 & 0.0 & 2 & 13.3 & Rhizopus stolonifer, Rhizopus nigricans, Mucor spp. \\
\hline & Corn bread $(n=12)$ & 0 & 0.0 & 1 & 8.3 & Fusarium spp. \\
\hline \multirow[t]{2}{*}{ Dried fruits } & Dried fig $(n=42)$ & 0 & 0.0 & 8 & 19.05 & $\begin{array}{l}\text { A.flavus, A.fumigatus, A.niger, A.conicus, Mucor spp., A. } \\
\text { ochraceus, A.parasiticus, Fusarium solani, Rhizopus } \\
\text { oryzae }\end{array}$ \\
\hline & Total sample $=364$ & 6 & $1.65 \%$ & 33 & $9.06 \%$ & \\
\hline
\end{tabular}


Maximum Recovery Diluent (MRD, Merck) was used for the homogenization and/or dilutions of food materials for the enumeration and identification of Staphylococcus aureus (ISO 6888-3:2003). Egg-yolk tellurite emulsion was added into Baird-Parker Agar base. Serial dilutions from $10^{-2}$ to $10^{-6}$ were inoculated onto Baird-Parker Agar (Merck) plates by spread plate technique. Plates were incubated at $37^{\circ} \mathrm{C}$ for $24 \mathrm{~h}$. Black and bright colonies with 0.5-1.5 mm radius were suspected as $S$. aureus. Confirmation was performed by coagulase test.

\section{Fungal Isolation and Identification}

Homogenization of samples for total yeast and mold count (ISO 6611:2004) was performed in $0.1 \%$ Peptone Water (PW, Merck). Dilutions (1:10) of $10^{-2}$ to $10^{-6}$ were inoculated onto Dichloran Rose Bengal Chloramphenicol (DRBC, Merck) agar with a spread plate method. Inoculated plates were incubated at $28^{\circ} \mathrm{C}$ for $7-14$ days. Sub-cultures were taken by transferring individual fungal colonies onto both Czapek-Dox agar (CZP) and Malt extract agar (MEA) media, respectively, and incubated at $28^{\circ} \mathrm{C}$ for 7 days (for identification and morphological observations). After the 7 th day of incubation the fungal cultures were observed both visually and under a microscope. For microscopic morphology, lactophenol blue solution was applied to microscope slides, colonies were transferred for identification and images were compared with the literature (Fassatiova, 1986; Pitt, and Hocking, 1997; Pitt, 1988; Samson et al., 2004) considering the structure of the mycelium, conditions of branches, rough and smooth stripe conditions, presence of conidiophores, sclerotia and shapes. Confirmation of species was carried out by the fungal slide culture method using Sabouraud medium.

\section{Results and Discussion}

Microbial food safety is an increasing public concern worldwide to collect information along the food chain, where primary production represents a critical point for contamination spreading.

A total of 665 samples on 13 different food categories were analyzed for pathogens detection and for the levels of toxigenic molds between 2005 and 2009. These samples included raw materials like fish, chicken, calf meat, processed foodstuffs such as minced meat, deserts, cheese, bread, traditional Turkish foods namely chilli pepper, hazelnut, yoghurt, dried fig, various seasonings, frozen foods and water types like spring water, well water that are used both during food processing and drinking.

\section{Pathogen Detection in Food Samples}

In this study, six food-borne pathogens were analysed in 301 food samples. Generally, growth of pathogens was observed in 16 out of 301 food samples. Few studies focused on multi-pathogen research in different food types in Turkey. Some other examples obtained from the literature can be given as Salmonella spp. occurrence on pork and other meat products (Prendergas et al., 2008; Jordan et al., 2006), Yersinia enterocolitica in slaughtered pigs (Fredriksson-Ahomaa et al., 2009), Listeria spp. in various food types (Farber et. al, 1989), Listeria spp. in ready-to-eat food (Gombas et.al., 2003), Escherichia coli O157:H7 serotype in dairy herds (Zhao et al., 1995), and in raw meats, raw cow's milk and raw-milk cheeses (Cagney et al., 2004). Detection of pathogens in foods has a significant importance due to their health hazard in terms of severe diseases. As a primary foodborne pathogens, E.coli O157:H7 cause severe diseases including hemorrhagic colitis, hemolytic-uremic syndrome, and non-bloody diarrheal illnesses (Ratnam et al., 1998; Lim et al., 2010), Salmonella spp. mainly localized and effect the gastrointestinal tract as gastroenteritis, or become generalized as a septicemia and affect several organ systems (Ekperigin and Nagaraja, 1998). As another important pathogen in foods, Listeria spp. causes listeriosis especially important in pregnants with regard to devastating effect to fetus. Recent outbreaks demonstrated that practically $L$. monocytogenes can cause gastroenteritis in otherwise healthy individuals and more severe invasive disease in immunocompromised patients (Barbuddhe and Chakraborty, 2009).

Among pathogen species, the most prevalent (\%) pathogen detected in samples was Salmonella with a ratio of $4 / 301(1.33 \%)$ as shown in Table 1 . The following common pathogens $S$. aureus, $C l$. perfringens, $L$. monocytogenes, B. cereus and E. coli $\mathrm{O} 157: \mathrm{H} 7$ had shown contamination ratios of $1.33 \%, 1.00 \%, 0.66 \%$, $0.66 \%$ and $0.33 \%$, respectively. S. aureus, $L$. monocytogenes, $\mathrm{Cl}$. perfringens and $B$. cereus were detected mainly in cheese and meat products.

Our results are in good agreement with Chapman et al. who isolated Escherichia coli O157:H7 serotype in cattle and sheep at slaughter, on beef and lamb carcasses and in raw beef and lamb products in South Yorkshire. E. coli 0157:H7 was isolated from $620(12.9 \%)$ of 4800 cattle, $100(7.4 \%)$ of 7200 sheep, $21(1.4 \%)$ of 1500 beef carcasses, $10(0.7 \%)$ of 1500 lamb carcasses and from 22 $(0.44 \%)$ of 4983 raw meat products (Chapman et al., 2001). Another study of which results are in line with these results was performed in Morocco. Badri et al. (2009) shows that the faecal E. coli strains were isolated from ground beef $(n=140)$, turkey $(n=200)$, sausage $(n=120)$, seafood $(n=60)$, domestic water $(n=35)$ and well water $(n=50)$. The prevalence of $E$. coli was $48 \%, 45 \%$, $35.5 \%, 30 \%, 8.3 \%, 0 \%$, for well water, ground beef, turkey, sausage, sea food and domestic water, respectively (Badri et.al., 2008).

Both Salmonella spp. and E.coli O157:H7 serotype were the pathogens belonging to the Enterobacteriaceae family. E. coli species were especially recovered from meat products and some fruits and vegetables especially grown on soil. Salmonella spp. was mostly isolated from chicken and minced chicken meat and some raw vegetables like parsley and spinach. This is in accordance with the findings of Berends et al. 1998, that the composition of the bacterial flora on meat at retail outlets is highly reflective of the initial contamination occurring during slaughter, though this and other studies (Prendergast et al., 2008) have clearly demonstrated that there are many opportunities for cross contamination with Salmonella spp. in meat cutting rooms, butchers and supermarkets. 
In another study, various retail foods were analyzed for the presence of Listeria spp. One hundred ten samples of vegetables including lettuce, celery, tomatoes, and radishes, and 14 samples of pasteurized milk, were found to be free of L. monocytogenes. In contrast 9 of 16 $(56.3 \%)$ chicken legs, 38 of $44(86.4 \%)$ ground meats, and 6 of $30(20 \%)$ fermented sausages contained the organism. 530 samples of ice cream products obtained at the manufacturing level, only 2 were positive for $L$. monocytogenes (Farber et al., 1989).

In a study carried out in Spain, occurrence of Salmonella, Campylobacter, Listeria and Shiga toxin producing $E$. coli was investigated in 60 flocks of freerange chicken from 34 farms. Prevalence for Salmonella spp. was found low (1.7\% of flocks). Campylobacter was the most prevalent of the four pathogens, isolated in 24 of the 34 farms $(70.6 \%)$.

Animal-based products like cheese and meat are prone to faecal contamination from animal. Irrigation with contaminated water and some animals like birds and chickens are the main sources for the contamination of vegetables and fruits (Coia et al., 2001). These results have all shown that foodborne illnesses and some common-source outbreaks are inevitable. The results of this study emphasize the value of routinely testing samples for Enterobacteriaceae as indicators of hygiene. Moreover, some precautions should be applied to ensure food safety including prevention of cross contamination, temperature control during storage and distribution, personal hygiene and sanitation of food processing equipments and plant.

\section{Molds Detection in Food Samples}

Mycotoxins are secondary metabolites of molds that have adverse effects on humans. Exposure to mycotoxins is mostly by ingestion, but also occurs by the dermal and inhalation routes. The diseases caused by exposure to mycotoxins are known as mycotoxicoses. Other than mycotoxicoses, mycotoxins have various acute and chronic effects on humans and animals (especially monogastrics) depending on species and susceptibility of an animal within a species (Peraica et al., 1999).

Fungal spoilage of randomly selected food samples are shown in Table 2. Overall mold spoilage of 364 food samples was $9.06 \%(33 / 364)$ and yeast spoilage was $1.65 \%$ (6/364). As shown in the Table 2, dried fig, chilli pepper, flour, white cheese, wheat bread and hazelnut, were the main food products prone to fungal spoilage. Yeast species were especially detected in cheese varieties. The most susceptible food types to yeast growth were milk products, deserts and seasonings.

Fungal spoilage ratio of dried fig was $19.05 \%(8 / 42)$ and $17.14 \%(6 / 35)$ for chilli pepper. They were followed by wheat bread, white cheese and flour with the same contamination ratio of $13.3 \%$ and hazelnut with a ratio of $8.57 \%$. These data showed that, mold contamination occures especially during the drying period due to the effect of humidity and temperature. Results of dried fig are similar to Leong et al. (2003) in which members of Aspergillus section Nigri were enumerated and identified in a total of 806 samples comprising both fresh fruit as well as partially-dried and fully-dried grapes. Aspergillus aculeatus, A. carbonarius and A. niger were commonly isolated.

Similar results were found in another study of Mislivec et al. (1979) where a survey conducted for the number of different mold species in 10 types of healthy foods labeled organically grown (wheat flour, corn meal, brown rice, figs, split peas, pinto beans, soybeans, walnuts, pecans, and peanuts) and more than 65 species, were encountered. The mold flora was dominated by Aspergillus glaucus, Aspergillus niger, Aspergillus flavus, Aspergillus candidus, Penicillium cyclopium, and Penicillium viridicatum. Isolates of the genera Alternaria, Cladosporium, Fusarium, and Helminthosporium also occurred in certain foods.

Our results suggest that during harvesting, drying and storage, food products have high levels of mold growth during processing stages and may have significant contamination with mycotoxin. Therefore, to ensure mycotoxin contamination, first mold spoilage should be prevented by following good agricultural practices during both pre-harvest and post-harvest conditions especially in agricultural foods. Other requirements to prevent contamination are appropriate drying techniques, maintaining proper storage facilities and taking care not to expose the foods (espeacially grains, seeds or unpackaged foods) to moisture during transport and marketing.

\section{Conclusion}

The present study was the first in which multi foodborne pathogen and mold species were examined in a great many food types. Data obtained from this study revealed the natural occurrence of foodborne pathogens and mold species in randomly selected food samples and therefore indicate that if there is a breach of current food safety management systems there can be widespread contamination. The results of this study suggest that faecal contamination of water and food materials during production needs to be prevented. These findings have also implications for the use of these surveillance data in developing evidence-based food policy.

In conclusion, all food business operators in Turkey must comply with Total Quality Management (TQM), which requires them to establish and operate food safety management systems based on the principles of Hazard Analyses and Critical Control Points (HACCP). In addition, monitoring schemes implemented in Turkey are needed to evaluate trends in the occurrence of these microorganisms and to measure the efficiency of the strategies implemented to reduce their carriage from farm to the production end of the food safety continuum. 


\section{Acknowledgements}

I gratefully acknowledge TUBITAK-ATAL (Ankara Test and Analyses Laboratory) Directorate for financial support and Prof. Dr. Kadir Halkman for his tremendous help and consultancy.

\section{References}

Andrews W. 1992. Manual of food quality control. 4. Rev. 1. Microbiological analysis. Food and Drug Administration. FAO Food Nutr Pap., 14(4): 1-338. PMID: 1426189

Amézqueta S, González-Peñas E, Murillo-Arbizu M, López de Cerain A. 2009. Ochratoxin A decontamination: A review. Food Control, 20: 326-333. DOI: 10.1016/j.foodcont.2008.05.017

Anonymous, 2005. Anonymous, Trends and Sources of Zoonotic Agents in Animals, Feedstuffs, Food and Man in the European Union and Norway in 2003, SANCO/339/2005 European Commission, Brussels.

Badri S, Filliol I, Carle I, Hassar M, Fassouane A, Cohen N. 2009. Prevalence of virulence genes in Escherichia coli isolated from food in Casablanca (Morocco). Food Control, 20: 560-564. DOI: 10.1016/j.foodcont.2008.08.015

Barbuddhe SB, Chakraborty T. 2009. Listeria as an enteroinvasive gastrointestinal pathogen. Curr Top Microbiol Immunol., 337: 173-95. DOI: 10.1007/978-3-642-01846-6_6; PMID: 19812983

Berends BR., Van Knapen F, Mossel DAA, Burt SA, Snijders JMA. 1998. Salmonella spp. on pork at cutting plants and at the retail level and the influence of particular risk factors. Int J Food Microbiol., 44: 207-217. DOI: 10.1016/S0168-1605(98)00122-6

Brito JR, Santos EM, Arcuri EF, Lange CC, Brito MA, Souza GN, Cerqueira MM, Beltran JM, Call JE, Liu Y, Porto-Fett AC, Luchansky JB. 2008. Retail survey of Brazilian milk and Minas Frescal cheese and a contaminated dairy plant to establish prevalence, relatedness, and sources of Listeria monocytogenes isolates. Appl. Environ. Microbiol., 74: 49544961. DOI: 10.1128/AEM.01828-07; PMID: 18502929.

Cagney C, Crowley H, Duffy G, Sheridan JJ, O’Brien S, Carney E, Anderson W, McDowell DA, Blair IS, Bishop RH. 2004. Prevalence and numbers of Escherichia coli O157:H7 in minced beef and beef burgers from butcher shops and supermarkets in the Republic of Ireland. Food Microbiol., 21: 2203-212. DOI: 10.1016/S0740-0020(03)00052-2.

CAST 2003. Mycotoxins: Risks in plant, animal, and human systems. Council for Agricultural Science and Technology, USA.

Chapman PA, Cerda'n Malo AT, Ellin M, Ashton R, Harkin MA. 2001. Escherichia coli $\mathrm{O} 157$ in cattle and sheep at slaughter, on beef and lamb carcasses and in raw beef and lamb products in South Yorkshire, UK. Int J Food Microbiol., 64: 139-150. DOI: 10.1016/S0168-1605(00)00453-0

Delhalle L, Saegerman C, Farnir F, Korsak D, Maes N, Messens WL, Daube G. 2009. Salmonella surveillance and control at post-harvest in the Belgian pork meat chain. Food Microbiol, 26: 265-271.DOI: doi:10.1016/j.fm.2008.12.009

Ekperigin HE, Nagaraja KV. 1998. Microbial food borne pathogens. Salmonella. Vet Clin North Am Food Anim Pract., 14: 17-29. PMID: 9532664
Esteban JI, Oporto B, Aduriz G, Juste Ramón A, Hurtado A. 2008. A survey of food-borne pathogens in free-range poultry farms. Int J Food Microbiol., 123: 177-182. DOI: 10.1016/j.ijfoodmicro.2007.12.012.

Farber JM, Sanders GW, Johnston M. 1989. A survey of various foods for the presence of Listeria species. J Food Prot., 52: 456458.

Fredriksson-Ahomaa M, Stolle A, Stephan R. 2007. Prevalence of pathogenic Yersinia enterocolitica in pigs slaughtered at a Swiss abattoir._Int J Food Microbiol., 119: 207-212. DOI: 10.1016/j.ijfoodmicro.2007.07.050

Hageskal G, Lima N, Skaar I. 2009. The study of fungi in drinking water. Mycol. Res., 113: $165-172$.

Gombas DE, Chen Y, Clavero Rocelle S, Scott VN. 2003. Survey of Listeria monocytogenes in ready-to-eat foods. J Food Prot., 66: 559-569. PMID: 12696677

Coia JE, Johnston Y, Steers NJ, Hanson MF. 2001. A survey of the prevalence of Escherichia coli $\mathrm{O} 157$ in raw meats, raw cow's milk and raw-milk cheeses in south-east Scotland. Int J Food Microbiol., 66: 63-69. DOI: 10.1016/S0168-1605(00)00490-6

Jordan E, Egan J, Dullea C, Ward J, McGillicuddy K, Murray G, Murphy A, Bradshaw B, Leonard N, Rafter P, McDowell S. 2006. Salmonella surveillance in raw and cooked meat and meat products in the Republic of Ireland from 2002 to 2004. Int J Food Microbiol., 112: 66-70. DOI: 10.1016/j.ijfoodmicro.2006.05.013

Leong SL, Hocking AD, Pitt JI. 2003. Occurrence of fruit rot mold (Aspergillus section Nigri) on some drying varieties of irrigated grapes. Aust J Grape Wine Res., 10: 183-188.

Lim JY, Yoon J, Hovde CJ. 2010. A brief overview of Escherichia coli O157:H7 and its plasmid. J Microbiol Biotechnol., 20: 514. PMID: 20134227.

Mislivec PB, Bruce VR, Andrews WH. 1979. Mycological survey of selected health foods. Appl. Environ. Microbiol., 37: 567571.

Speijers GJA, Speijers MHM. 2004. Combined toxic effect of mycotoxins. Toxicol Lett., 153: 91-98. DOI: 10.1016/j.toxlet.2004.04.046; PMID: 15342085

Peraica M, Radic B, Lucic A, Pavlovic M. 1999. Toxic effects of mycotoxins in humans. Bull World Health Organ., 77: 754-766.

Prendergast, DM, Duggan SJ, Gonzales-Barron U, Fanning S, Butler F, Cormican M, Duffy G. 2009. Prevalence, numbers and characteristics of Salmonella spp. on Irish retail pork. Int J Food $\begin{array}{lll}\text { Microbiol., } & \text { 131: }\end{array}$ DOI:10.1016/j.ijfoodmicro.2009.03.003

Ratnam S, March SB, Ahmed R, Bezanson GS, Kasatiya S. 1988. Characterization of Escherichia coli serotype O157:H7. J Clin Microbiol., 26: 2006-2012. PMID: 3053758

Villa P, Markaki P. 2009. Aflatoxin $B_{1}$ and ochratoxin A in breakfast cereals from Athens market: Occurrence and risk assessment. Food Control, 20: 455-461. DOI: 10.1016/j.foodcont.2008.07.012

Wogan GN, Raymond SP, 1969. Time course of alterations of rat liver polysome profiles induced by aflatoxin $B_{1}$. Biochem Pharmacol, 18: 2357-2361.

Zhao T, Doyle MP, Shere J, Garber L. 1995. Prevalence of enterohemorrhagic Escherichia coli $\mathrm{O} 157: \mathrm{H} 7$ in a survey of dairy herds. Appl. Environ. Microbiol., 61: 1290-1293. PMC167385 